\title{
Determination of phytoplankton absorption coefficient in natural seawater samples: evidence of a unique equation to correct the pathlength amplification on glass-fiber filters
}

\author{
B. Arbones ${ }^{1, *}$, F. G. Figueiras ${ }^{1}$, M. Zapata ${ }^{2}$ \\ ${ }^{1}$ Instituto de Investigacións Marin̄as, CSIC, Eduardo Cabello 6, E-36208 Vigo, Spain \\ ${ }^{2}$ Centro de Investigacións Mariñas, Consellería de Pesca, Marisqueo e Acuicultura, Pedras de Corón, s/n, \\ E-36600 Vilanova (Pontevedra), Spain
}

\begin{abstract}
Estimations of the spectral absorption coefficients of phytoplankton in the sea, based on the spectrum of absorption of particles retained on a filter, require a correction for pathlength amplification in the glass fibre filter ( $\beta$ factor). The relationship between the optical density in suspension and 'on filter' is misleading due to the hysteresis effect. This effect is reduced on eliminating the absorption due to non-pigmentary material, minimising the dependency of the $\beta$ factor on wavelength. A general quadratic equation, $O D_{\text {sus }}(\lambda)=0.38 O D_{\text {filter }}(\lambda)+0.42 O D^{2}$ titter $(\lambda)\left(r^{2}=0.97, n=15600\right)$, was obtained on comparing 52 pairs of spectra of 9 marine phytoplankton species. The algorithm was validated against natural samples, obtaining a $1 \%$ average error Comparisons between Cleveland \& Weidemann's equation (1993, Limnol Oceanogr 38:1321-1327) and the equation obtained in this study provided a $2 \%$ average difference, suggesting that a unique equation can be useful in determining the phytoplankton absorption coefficient in seawater samples. We compared the absorption coefficients obtained by spectra reconstructed from the pigment content in seawater samples with those obtained with spectra on $\mathrm{GF} / \mathrm{F}$ filters and $\beta$-corrected. Our results indicate that the spectra-reconstructed approach is only suitable when the sample consists of small quasi-spherical cells. For coastal-upwelling samples which are mainly composed of large cells the approach overestimates the package effect.
\end{abstract}

KEY WORDS: Phytoplankton absorption Pathlength amplification · Hysteresis effect

\section{INTRODUCTION}

Mathematical models of algal photosynthesis and growth are important in the prediction of global- and regional-scale variations in marine primary productivity and are used in the conversion of chlorophyll a (chl a) data obtained by remote sensing to primary production and algal growth. The first obstacle in developing these models is the lack of a precise measure to determine the phytoplankton absorption coefficient $\left[a_{\mathrm{ph}}(\lambda), \mathrm{m}^{-1}\right]$ in natural samples (see Table 1 for a list of symbols used in this paper). Phytoplankton cell con-

•E-mail: belen@iim.csic.es centration in the ocean is very low, which makes it necessary to concentrate the particulate matter in suspension in order to measure the light absorption.

The first approaches to the problem (Shibata et al. 1954, Shibata 1958), determined the light attenuation in the biological matter in suspension using an opal glass plate as a diffuser. Yentsch (1962) developed a method consisting of collecting the particulate matter in a membrane filter which was afterwards cleared with cedar oil. Later on, Trüper \& Yentsch (1967) concentrated bacterial cultures on a qlass-fiber filter, measuring the absorption directly on the wet filter. Nowadays, this method, which uses a glass-fiber filter both as an optical diffuser and to concentrate the particulate 
Table 1. Main symbols and units used in the text

\begin{tabular}{|c|c|}
\hline$\lambda$ & Wavelength, nm \\
\hline$O D_{\text {sus }}(\lambda)$ & Optical density of sample in suspension, wavelength dependent \\
\hline$O D_{\text {filter }}(\lambda)$ & Optical density of sample on filter, wavelength dependent \\
\hline$O D_{\text {fillier }: \mathrm{cm}}(\lambda)$ & Optical density of sample to obtain $1 \mathrm{~cm}$ light path \\
\hline $\mathrm{OD}_{\mathrm{p}}(\lambda)$ & Optical density of the particles collected on the filter \\
\hline$O D_{d}(\lambda)$ & Optical density of the nonalgal material \\
\hline$X$ & Pathlength in meters, obtained from V/S \\
\hline$\beta$ & Pathlength amplification factor \\
\hline$a_{\text {sus }}(\lambda)$ & Spectral absorption coefficient of sample in suspension, $\mathrm{m}^{-1}$ \\
\hline$a_{\text {filter }}(\lambda)$ & Spectral absorption coefficient of sample on filter, $\mathrm{m}^{-1}$ \\
\hline$V$ & Volume of filtered of sample, $\mathrm{m}^{3}$ or $\mathrm{cm}^{3}$ \\
\hline$S$ & Clearance area of the filter, $\mathrm{m}^{2}$ or $\mathrm{cm}^{2}$ \\
\hline$a_{p}(\lambda)$ & Absorption coefficient of total particulate matter, $\mathrm{m}^{-1}$ \\
\hline$a_{d}(\lambda)$ & Absorption coefficient of nonalgal matter, $\mathrm{m}^{-1}$ \\
\hline$a_{p h}(\lambda)$ & Absorption coefficient of phytoplankton, $\mathrm{m}^{-1}$ \\
\hline$a_{\text {ph-sol }}(\lambda)$ & Absorption coefficient of phytoplankton estimated by HPLC, $\mathrm{m}^{-1}$ \\
\hline$a^{*}{ }_{p h-s o l}(\lambda)$ & Chl-specific absorption coefficient of phytoplankton estimated by HPLC, $\mathrm{m}^{2} \mathrm{mg}^{-1}$ \\
\hline$a_{\mathrm{ph}}^{\hat{n}}(\hat{\lambda})$ & Chi-specific absorption coefficient of phytopiankion esiindated by HPLC with the package effect, $\pi^{2}{ }^{2} \overline{m g}^{-1}$ \\
\hline$C_{j}$ & Volume-based concentrations of pigment $i, \mathrm{mg} \mathrm{m}^{-3}$ \\
\hline$a_{1} "(\lambda)$ & Pigment-specific absorption coefficient of pigment $i, \mathrm{~m}^{2} \mathrm{mg}^{-1}$ \\
\hline$C_{1}$ & Intracellular chlorophyll a content per unit cell volume, $\mathrm{mg} \mathrm{m}^{-3}$ \\
\hline$a_{m}(\lambda)$ & Cell material absorption coefficient, $\mathrm{m}^{-1}$ \\
\hline$d$ & Diameter of a sphere of volume equivalent to the mean cell volume, $\mathrm{m}$ \\
\hline$\rho^{\prime}$ & The dimensionless product of the absorption coefficient of the cell material $\left[a_{c m}(\lambda)\right]$ and the cell diameter $(d)$ \\
\hline$Q_{a}{ }^{*}$ & Fractional reduction of pigment absorption due to the package effect, dimensionless \\
\hline
\end{tabular}

matter, is the most widely employed to measure the light absorption in phytoplankton natural populations.

Light absorption in natural samples concentrated on a filter is not only due to the phytoplankton but also to non-photosynthetic materials (inorganic suspended matter, phytoplankton debris, living heterotrophs such as bacteria), and besides, there exists an effect of pathlength amplification due to the multiple scattering produced on the filter. Therefore, the absorption spectrum in natural samples concentrated on a filter needs correction for both of the following aspects: (1) it is necessary to estimate the absorption due to non-photosynthetic material, either by measuring the absorption spectrum of the matter collected on a filter once the pigments have been extracted with methanol (Kishino et al. 1985) or by a statistical estimation based on relationships of optical densities from the particle absorption spectrum at wavelengths where the absorption is mainly due to nonalgal material (Morrow et al. 1989, Bricaud \& Stramski 1990); (2) we must also correct the 'pathlength amplification' effect or ' $\beta$ factor' evidenced by Butler (1962), which is defined as the ratio of the optical to geometrical pathlength and can be estimated from the following relationship:

$$
\beta=a_{\text {fllter }}(\lambda) / a_{\text {sus }}(\lambda)
$$

$a_{\text {filter }}(\lambda)$ and $a_{\text {sus }}(\lambda)$ being the spectral absorption coefficients measured on filter and in suspension, respectively.
Even though the methods for determining the absorption spectrum of nonalgal matter are widely accepted and used (Kishino et al. 1985, 1986, Bricaud \& Stramski 1990), there is a great controversy about the $\beta$ factor. Several previous studies assumed a constant factor (Kiefer \& SooHoo 1982, Lewis et al. 1985, Kishino et al. 1986). Kishino et al. (1985) determined $\beta$ to vary between 2.43 and 4.71 with species and suggested nearly constant $\beta$ with wavelength. Mitchell \& Kiefer $(1984,1988)$ demonstrated that the correction factor is not constant, but varies with the optical density of the particles on the filter and with different filter types

In a later study, Bricaud \& Stramski (1990) compared the optical density (OD) of natural samples in suspension with that measured 'on filter', showing a 'hysteresis effect', which means that for the same $O D_{f i t e r}(\lambda)$, the $\beta$ value varied with wavelength.

However, Cleveland \& Weidemann (1993) did not find such a hysteresis effect and they proposed a general quadratic relationship:

$$
\mathrm{OD}_{\text {sus }}(\lambda)=0.3780 \mathrm{D}_{\text {filter }}(\lambda)+0.523 \mathrm{OD}_{\text {filter }}^{2}(\lambda)
$$

suggesting that this equation could have a universal character because the average differences among the values of $O D_{\text {sus }}(\lambda)$ predicted by their equation and the respective values of $\mathrm{OD}_{\text {sus }}(\lambda)$ measured in suspension were $2 \%$ 
In view of the aforementioned controversy about the $\beta$ factor, this study was focused on the description and evaluation of $\beta$ variability, as it is a key point for estimating the phytoplankton absorption coefficient in natural samples and consequently for estimating the primary production.

Another possible alternative for estimating the phytoplankton absorption coefficient was developed by Bidigare et al. (1990). It consists of the reconstruction of absorption spectra from pigment concentrations determined by high performance liquid chromatography (HPLC) analysis. This methodology was shown to be adequate for oceanic waters in which the phytoplankton community was composed of small rounded forms. Here, we compare the phytoplankton spectra reconstructed according to Bidigare et al. (1990) against the spectra determined on GF/F filters and corrected for pathlength amplification in coastal-upwelling samples, where the phytoplankton community is composed essentially of large diatoms and dinoflagellates with a high diversity of forms.

\section{MATERIALS AND METHODS}

The $\beta$ factor can be determined by comparing the optical density spectrum of a sample measured on a filter $\left[O D_{\text {filter }}(\lambda)\right]$ with that measured in suspension $\left[O D_{\text {sus }}(\lambda)\right]$.

The absorption spectra were determined with a single beam spectrophotometer (Beckman DU 650), from 350 to $755 \mathrm{~nm}$ at $1 \mathrm{~nm}$ spectral bandwidth. The spectrophotometer automatically corrected for the blank which was stored prior to analyses. The wavelength repeatability and accuracy of this instrument is $\pm 0.2 \mathrm{~nm}$ and $\pm 0.5 \mathrm{~nm}$, respectively. The photometry accuracy of this instrument as determined by the manufacturer is $\pm 0.005 \mathrm{OD}$ at a signal level of $1 \mathrm{OD}$ by using an NIST $930 \mathrm{D}$ solid filter at $546 \mathrm{~nm}$.

Nine species of unialgal phytoplankton cultures growing in $f / 2$ enriched sterile seawater medium (Guillard \& Ryther 1962) under 'cool-white' fluorescent lamps on a 12:12 h light/dark cycle were used to determine the $\beta$ amplification factor.

The accuracy of our $\beta$ corrections was verified by comparing $\mathrm{OD}_{\text {sus }}$ of natural samples collected in the Ría de Vigo (NW of Iberian Peninsula) against $O D_{\text {sus }}$ deduced from $O D_{\text {iiter }}$ readings corrected for pathlength amplification. These samples were distributed along the main temporal phytoplankton succession in the area to be sure that the 2 more abundant phytoplankton groups (diatoms and dinoflagellates) were sampled (Margalef et al. 1955, Figueiras \& Niell 1987). Because of the low density of phytoplankton in seawater, the natural samples require a previous concen- tration of the suspended material to make the cuvette measures possible. The samples were filtrated onto $0.2 \mu \mathrm{m}$ Nucleopore filters and the material was resuspended in a small volume of filtered seawater by direct rubbing with a smooth brush and 2 or 3 min of gentle ultrasonication (Kirk 1980, Davies-Colley 1983, Bricaud \& Stramski 1990). With the natural sample concentrated in a smaller volume the absorption spectra were measured in cuvette and on filter.

The absorption spectra in suspension of phytoplankton cultures and concentrated natural samples were measured in a $1 \mathrm{~cm}$ cuvette by a modified opal glass technique (Shibata 1958, Trüper \& Yentsch 1967, Kiefer \& SooHoo 1982). A GF/F wet filter situated at the back of the sample compartment, close to the photomultiplier, was used as a diffuser. Filtrated growth medium for algal cultures and seawater for natural samples were used as blanks, respectively.

To measure $\mathrm{OD}_{\mathrm{f} \downarrow \text { ter }}(\lambda)$ samples were filtrated onto GF/F filters under low vacuum using a variable volume according to the phytoplankton concentration. The filter was situated close to the photomultiplier, in the same position as the cuvette was located. The same volume of prefiltered culture medium or seawater was filtered again through a GF/F filter and this filter was used as a blank. The average of at least 3 spectra was used for the estimation of the amplification factor. In order to obtain the same light path $(1 \mathrm{~cm})$ in the filter and suspension samples the $\mathrm{OD}_{\text {filter }}$ was corrected according to:

$$
\mathrm{OD}_{\text {filter } 1 \mathrm{~cm}}(\lambda)=O D_{\text {filter }}(\lambda) /(V / S)
$$

where $V$ is the filtered volume and $S$ is the filtration area of the filter to give $1 \mathrm{~cm}$ light-path. In this way $\mathrm{OD}_{\text {filter } 1 \mathrm{~cm}}(\lambda)$ [hereafter $\left.\mathrm{OD}_{\mathrm{filter}}(\lambda)\right]$ only differs from $\mathrm{OD}_{\text {sus }}(\lambda)$ in the pathlength amplification factor, $\beta$.

To compare the phytoplankton absorption spectra obtained by using the $\beta$ correction algorithm with HPLC reconstructed spectra (Bidigare et al. 1990), 20 natural samples were used. Of these, 14 samples were collected in the Ría de Vigo from spring to autumn, and 6 in a spring cruise at the shelf break of the Galician coast (NW Spain). Phytoplankton identification and volume determinations were made on Lugol's iodine samples using composite sedimentation chambers and an inverted microscope. Several measurements were taken in at least 20 individuals for each species in each sample. To calculated the specific volume each species was assignied to one or several geometrical shapes according to Edler (1979).

Two aliquots of each sample were used to determine the $O D_{\text {filter }}(\lambda)$ and the spectra reconstruction approximation, respectively. The optical density of the phytoplankton $\left[O D_{\mathrm{ph}}(\lambda)\right]$ was determined by subtraction of the optical density of the nonalgal material $\left[O D_{d}(\lambda)\right]$ 
from optical density of the particles collected on the filter $\left[O D_{p}(\lambda)\right]$. The light absorption of the nonalgal material was measured after filter pigment extraction with absolute methanol (Kishino et al. 1985). The respective optical densities at $750 \mathrm{~nm}$ were subtracted from $O D_{p}(\lambda)$ and $O_{d}(\lambda)$ (Cleveland \& Weidemann 1993), and the absorption coefficients of phytoplankton, $\left[a_{\mathrm{ph}}\right.$ $\left.(\lambda), \mathrm{m}^{-1}\right]$, were estimated according to the relationship;

$$
a_{p h}(\lambda)=2.3\left(\operatorname{OD}_{p}(\lambda)-\mathrm{OD}_{\mathrm{d}}(\lambda)\right] / X \cdot \beta(\lambda)
$$

where 2.3 is a conversion factor from $\log _{10}$ to $\ln , X$ is the pathlength in meters obtained from $V / S$ and $\beta(\lambda)$ is the pathlength amplification factor.

The samples for HPLC pigment determination were filtered onto $25 \mathrm{~mm}$ GF/F filters and frozen until later analysis in the laboratory. Reverse-phase HPLC was used to separate and quantify phytoplankton chlorophylls ( $c h l a_{1}$ chl $b_{1}, c h l c_{1}+c_{2}+c_{3}$ ) and carotenoids (prasinoxanthun, zeoxanthin, diadinoxanthin, fucoxanthin, 19'hexanoyloxy-fucoxanthin) in samples (Garrido \& Zapata 1993). The reconstruction of phytoplankton spectral absorption coefficients $\left[a_{\text {ph-sol }}(\lambda), \mathrm{m}^{-1}\right]$ was made following Bidigare et al. (1990):

$$
a_{\mathrm{ph}-\mathrm{sol}}(\lambda)=\sum_{i=1}^{n} c_{i} a^{*},(\lambda)
$$

where $c_{i}\left(\mathrm{mg} \mathrm{m}^{-3}\right)$ are the volume-based pigment concentrations and $a^{*}{ }_{i}(\lambda)\left(\mathrm{m}^{2} \mathrm{mg}^{-1}\right)$ are the respective in vitro pigment absorption coefficients wavelengthshifted to match their in vivo maxima (Bidigare et al. $1989 a, b)$.

Spectra of extracted pigments are known to be higher in magnitude than absorption spectra of intact pigmented cells because of the package effect (Kirk 1983, Berner et al. 1989). The package effect of the reconstructed spectra was calculated by reversing the method described for calculating 'unpackaged' absorption spectra (Morel \& Bricaud 1981). The chlorophyll-specific absorption coefficients [ $\left.a^{*}{ }_{\mathrm{ph}-\mathrm{sol}}(\lambda)\right]$ and the intracellular chl a content per unit cell volume $\left(C_{1}\right.$ $\left.\mathrm{mg} \mathrm{m}^{-3}\right)$ were used to determine $a_{\mathrm{cm}}(\lambda)$, the cell material absorption coefficient, from the equation:

$$
a_{\mathrm{ph}-\mathrm{sol}}(\lambda)=\frac{a_{\mathrm{cm}}(\lambda)}{C_{1}}
$$

The chlorophyll-specific absorption coefficient taking into account the package effect, $a_{p h}^{\wedge}(\lambda)$, for the cell suspension, can then be calculated as:

$$
a_{\mathrm{ph}}^{\wedge}(\lambda)=a_{\mathrm{ph}-\mathrm{sol}}^{*}(\lambda) \cdot \frac{3}{2} \cdot \frac{Q_{a}(\lambda)}{a_{\mathrm{cm}}(\lambda) d}
$$

where $d$ is the diameter of a sphere of volume equivalent to the mean cell volume; and $Q_{a}(\lambda)$ is the absorption efficiency or fractional light absorption of the cell (Morel \& Bricaud 1981, Iturriaga et al. 1988). $Q_{a}$ is a function of the dimensionless property $a_{\mathrm{cm}} d\left(a_{\mathrm{cm}} d=\rho^{\prime}\right)$, and is given by van de Hulst (1957)

$$
Q_{a}=1+\frac{2 e^{-\rho^{\prime}}}{\rho^{\prime}}+2 \frac{e^{-\rho^{\prime}}-1}{\rho^{\prime 2}}
$$

The ratio of $a_{\mathrm{ph}}(\lambda)$ to $a^{*}{ }_{\mathrm{ph} \text {-sol }}(\lambda)$ [referred to as $Q_{\mathrm{a}}^{*}(\lambda)$ in Morel \& Bricaud 1981, and $F$ in Sathyendranath et al. 1987 ] is the fractional reduction of pigment absorption due to the package effect. Dividing Eq. (7) by Eq. (6)

$$
Q_{a}^{*}=\frac{3}{2} \cdot \frac{Q_{a}(\lambda)}{\rho^{\prime}}
$$

$Q^{*}$. may be also calculated as the ratio $a^{\cdot}{ }_{\mathrm{ph}}(\lambda)$ to $a^{*}$ ph-sol $(\lambda)$ (Nelson \& Prézelin 1990):

$$
Q_{a}^{*}(\lambda)=\frac{a^{*}{ }_{p h}(\lambda)}{a^{*}{ }_{p h-s o l}(\lambda)}
$$

Comparisons between $Q_{a}{ }_{a}(\lambda)$ calculated by Eq. (9) and according $\mathrm{lo}$ Eq. (10) permit estimation of the accuracy of assimilating the cell shape to a sphere to calculate the package effect.

\section{RESULTS AND DISCUSSION}

\section{Pathlength amplification factor determination}

Data analysis was restricted to the visible light region of the spectrum (400 to $700 \mathrm{~nm}$ ) every $1 \mathrm{~nm}$. As did Cleveland \& Weidemann (1993) we analysed $\mathrm{OD}_{\text {sus }}(\lambda)$ as a function of $\mathrm{OD}_{\text {ilter }}(\lambda)$, instead of analysing $\beta(\lambda)$ as a function of $\operatorname{OD}_{\text {filter }}(\lambda)$. Values of $\operatorname{OD}_{\text {filter }}(\lambda)>0.4$ were eliminated because our field data were always $<0.4$.

In the same way as Bricaud \& Stramski (1990), we have observed that the relationship between $O D_{\text {filter }}$ and $O D_{\text {sus }}$ is misleading, in the sense that for the same value of $O D_{\text {filter, }}$ the value of $O D_{\text {sus }}$ varies according to the wavelength. This 'hysteresis effect' appears on a larger or smaller scale in many spectra (Fig. 1), and is mainly located in the low green-yellow absorption regions of the spectra. In these regions the OD in cuvette is almost exclusively a result of cell material without pigments (cell walls, culture debris) because the pigment absorption is low or zero depending on pigment composition and culture cell concentration, while on filter the pigment signals are detected due to the amplification pathlength (Fig. 1). That means that when examining the spectra from 700 to $400 \mathrm{~nm}$ the $O D_{\text {sus }}$ from approximately $650-625 \mathrm{~nm}$ to $575-550 \mathrm{~nm}$ is almost constant while the $O D_{\mathrm{f} \downarrow t e r}$ is progressively decreasing (Fig. 1, left side). This phenomenon is transported to the plot of $O D_{\text {sus }}$ versus $O D_{\text {iilter }}$ as a loop (Fig. 1, right side) causing the $\mathrm{OD}_{\text {sus }}$ versus $O D_{\text {filter }}$ relationships between $575-550$ and $400 \mathrm{~nm}$ to start again 
from a displaced point in the graph. The hysteresis effect is more acute when the culture concentration is low, because optical density values in the region of low pigment absorption will then be close to the detection limit of the spectrophotometer, bringing 2 spectra closer, even crossing in some cases. To avoid this problem, Nelson $\&$ Robertson (1993) excluded the regions of very low absorbance ( 550 to $665,>680 \mathrm{~nm}$ ) in their regression analysis. These low absorbance regions vary according to the phytoplankton species. Thus Phaeodactylum tricornutum (Fig. 1) shows the minimum light absorption between 560 and $600 \mathrm{~nm}$, while Tetraselmis suecica and Dunaliella terciolecta have their lowest absorption in a shorter wavelength of the spectrum, between 520 and $560 \mathrm{~nm}$ (Fig. 1). These differences must be related to the pigment composition of the algae (Jeffrey 1980). The photosynthetic carotenoids of diatoms (Phaeodactylum tricornutum) absorb in the green-yellow region.

On the other hand, it was observed that for the same culture concentration, cultures in stationary phase showed a higher hysteresis effect than those growing in exponential phase, probably due to the relative increase of nonalgal matter (i.e. dead cells, structures).

The hysteresis effect seems to be due to the ratio of absorption by pigments to absorption by nonalgal matter in the sample. When this ratio is very low the hysteresis effect is more acute than when the pigment concentrations are higher.

As a way to prove whether our interpretation of the influence of the relative proportions of pigments and non-pigmentary material on the hysteresis effect is true, we corrected the original spectra for the nonpigmentary material. The correction was made by Bricaud \& Stramski's (1990) indirect estimation method of the relative contribution of algal and nonalgal matter.

Once the particle absorption spectra were corrected both on filter and in cuvette a reduction in the hysteresis effect was observed (Fig. 2). In those pairs of spectra with a minimum hysteresis effect, the correction by Bricaud \& Stramski's (1990) method estimated $\mathrm{OD}_{\mathrm{d}}(\lambda)=0$. suggesting that the original spectra had a very low amount of nonalgal matter.

Seawater natural samples belong to the group of spectra that present the strongest hysteresis effect due
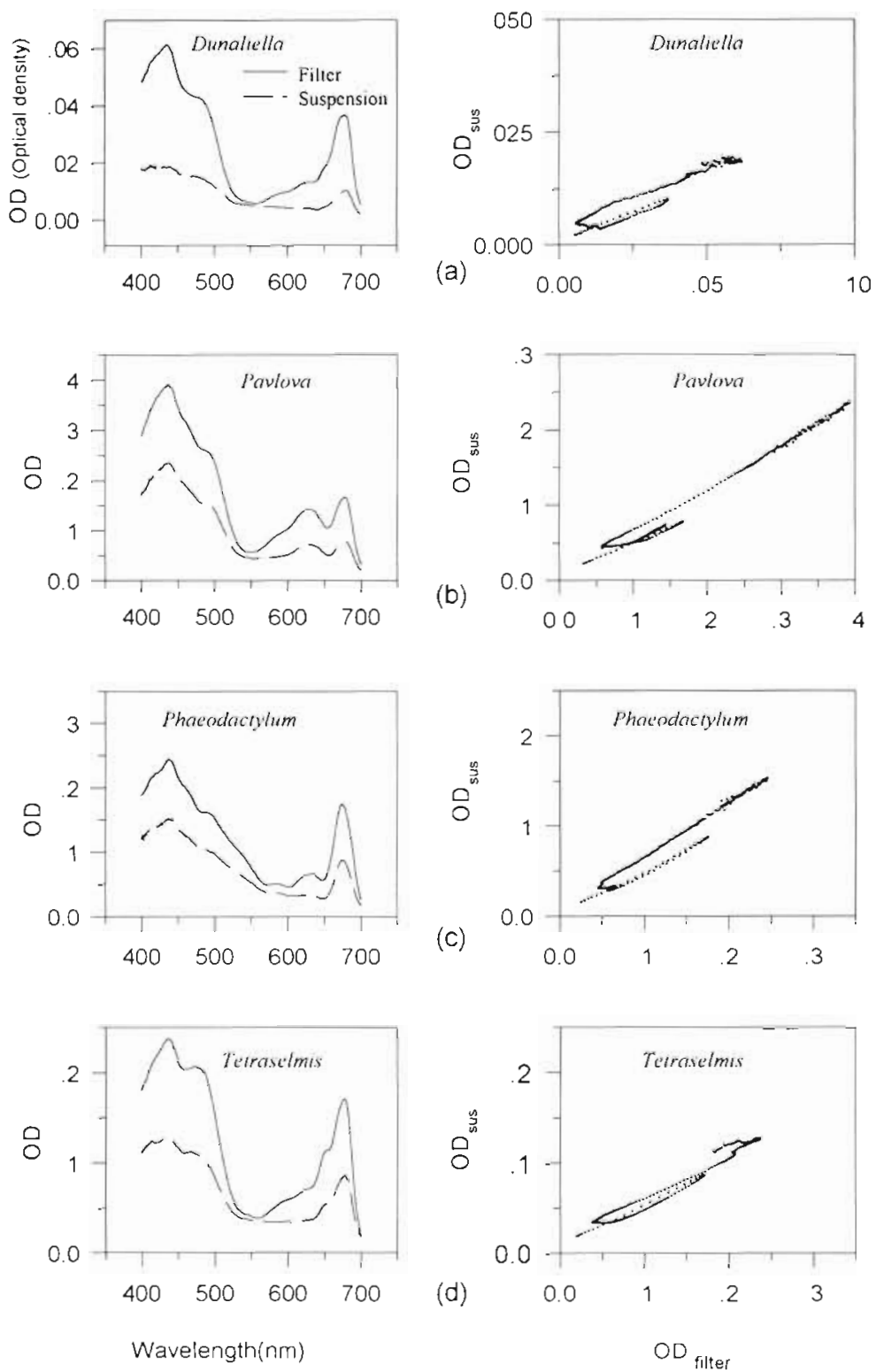

Fig. 1. Spectral values of $O D_{\text {filler }}$ (solid line) and $O D_{\text {sus }}$ (dashed line) for 4 phytoplankton cultures (left side). When $\mathrm{OD}_{\text {sus }}$ is plotted against $\mathrm{OD}_{\text {filter }}$ the 'hysteresis effect' can be observed (right side)

to the relatively high amount of nonalgal matter (heterotrophs, nonpigmented particles, detritus) present in seawater and to the low phytoplankton concentration. Fig. 2 shows the absorption spectra before and after correction. It can be seen how once the correction was done the $\mathrm{OD}_{\text {sus }}(\lambda)$ and $\mathrm{OD}_{\text {tilter }}(\lambda)$ relationships show considerable decreases in the hysteresis effect (Fig. 2f, h).

Therefore, the hysteresis effect was corrected before estimating the pathlength amplification factor with the phytoplankton cultures and its validation with the natural seawater samples. Another alternative could be to 


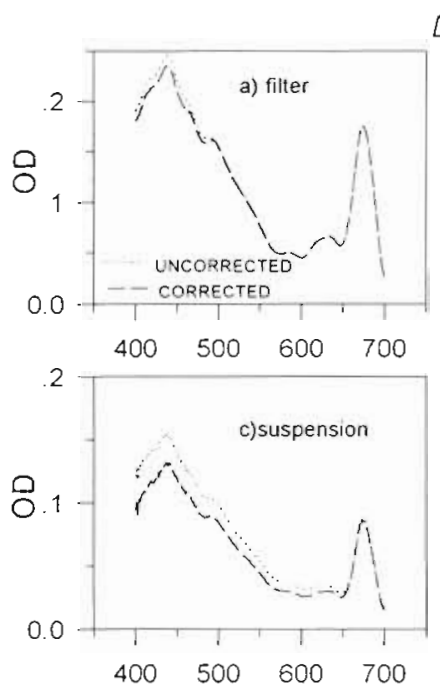

Dunaliella
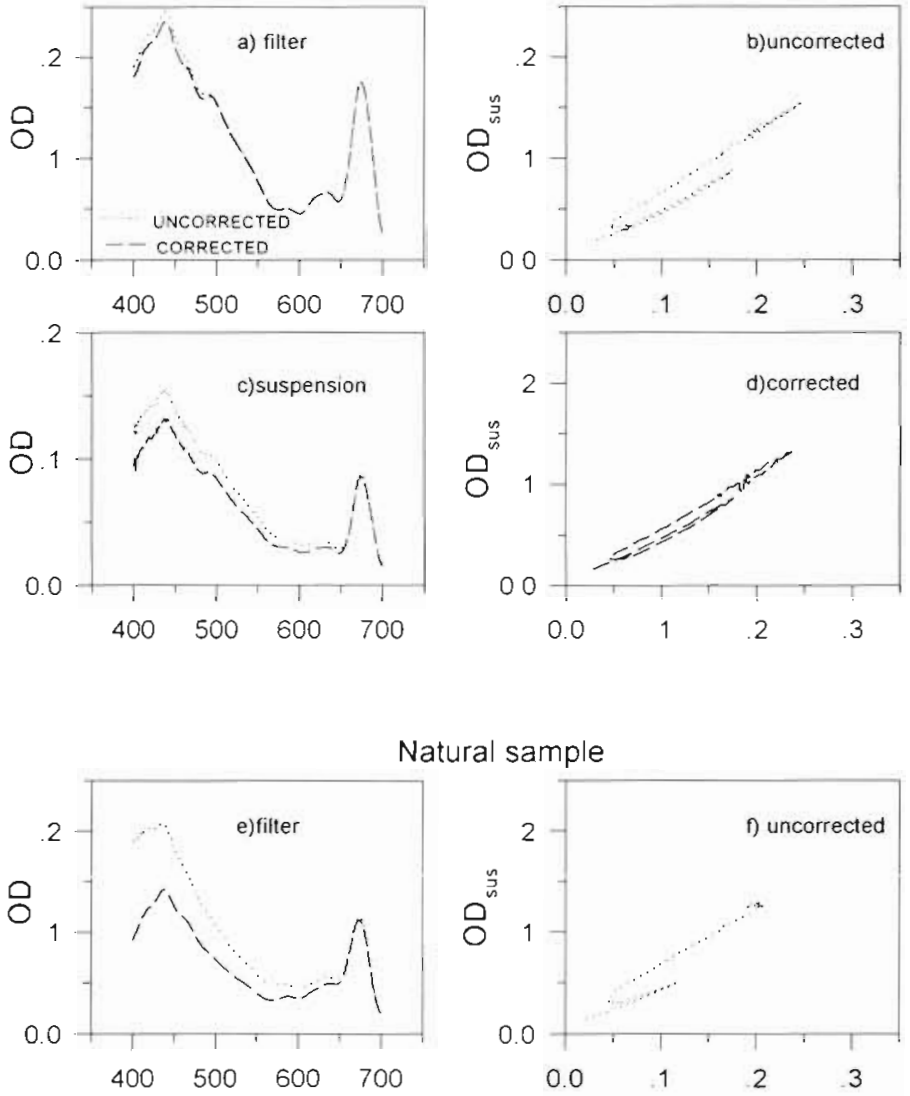

Natural sample
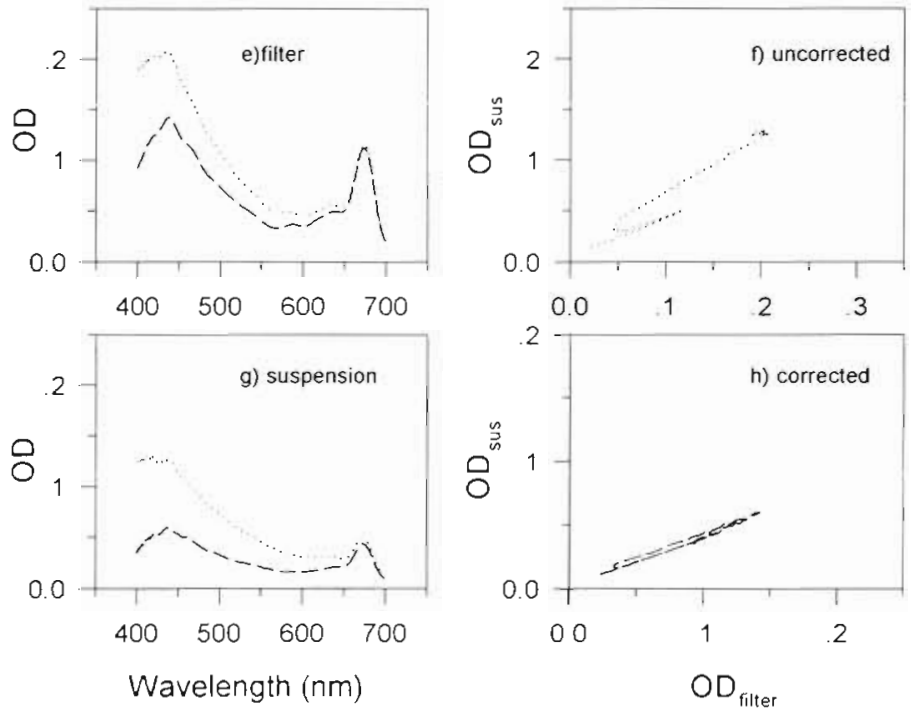

Fig. 2. Spectral values of OD uncorrected (dotted line) and corrected for nonalgal matter (Bricaud \& Stramski 1990) (dashed line) on filter $(a, e)$ and in suspension $(c, g)$. Optical densities in suspension as a function of optical densities on filters, before $(b, f)$ (dotted line) and after $(d, h)$ (dashed line) being corrected for nonalgal matter. Hysteresis effect was reduced after correction. Upper graphs are from Dunaliella tertiolecta culture; lower graphs are field samples

exclude low absorption regions from the statistical analysis (Nelson \& Roberson 1993).

\section{Statistical analysis}

In a first data analysis, each pair of spectra was fitted to a second degree equation, showing that the coefficients varied from one species to another (Fig 3 ) in a similar way to results found by Cleveland \& Weideman (1993) and Moore et al. (1995). Variations in the coefficients were also observed when all spectra of each species were pooled together showing higher oscillations in the second coefficient (Fig. 4). Several factors can explain this variability, which was mainly found in the cuvette measurements. The differing behaviours of swimming and sinking and the shape diversity of species can contribute to understanding of the heterogeneous response. Sinking would decrease the slope of the relation through a lower optical density in the cuvette. Species with stronger scattering due to cell wall shape and/or rigidity would produce a higher $O D_{\text {sus. }}$ Swim. ming can bring about a random relationship between $O D_{\text {sus }}$ and $O D_{\text {filler }}$.

A clear trend, however, was observed when adjusting pairs of spectra of different culture concentrations. The quadratic equation coefficients varied, reaching higher values in the most concentrated culture (Table 2). This trend was ciearer when the data were fitted to a straight line, because the second coefficient in the quadratic equation has a higher standard error than the slope of linear fit, due to the relatively few data points involved with high optical density. Nevertheless, when the 3 pairs of spectra of each species in Table 2 were combined, the 2 following (quite similar) equations were found:

$$
\begin{gathered}
\mathrm{OD}_{\text {sus }}(\lambda)=0.34 \mathrm{OD}_{\text {illter }}(\lambda)+0.46 \mathrm{OD}_{\text {filter }}^{2}(\lambda) \\
\left(\mathrm{r}^{2}=0.98\right) \\
\mathrm{OD}_{\text {sus }}(\lambda)=0.39 \mathrm{OD}_{\text {filter }}(\lambda)+0.47 \mathrm{OD}_{\text {filter }}^{2}(\lambda) \\
\left(\mathrm{r}^{2}=0.98\right)
\end{gathered}
$$

in Pavlova gyrans and in Emiliania huxleyi, respectively

Finally, a joint regression analysis was performed with 52 pairs of spectra of 9 different species: Chaetoceros gracilis ( $\mathrm{n}=3$ ), Dunaliella tertiolecta ( $\mathrm{n}=8)$, Emiliania huxleyi $(\mathrm{n}=7)$, $\mathrm{Mi}$ cromonas pursilla $(\mathrm{n}=7)$, Pavlova gyrans $(\mathrm{n}=3)$, Phaeodactylum tricornutum $(\mathrm{n}=7)$, Synechoccocus sp. $(n=5)$, Tetraselmis suecica $(n=7)$ and Rhodomonas baltica $(\mathrm{n}=5$ ) (Fig. 5). This analysis resulted in the following equation:

$$
\begin{aligned}
\mathrm{OD}_{\text {sus }}(\lambda)= & 0.38 \mathrm{OD}_{\text {filter }}(\lambda)+0.42 \mathrm{OD}_{\text {filter }}^{2}(\lambda) \\
& \left(\mathrm{r}^{2}=0.97, \mathrm{n}=15600\right)
\end{aligned}
$$

where the first coefficient (giving information about the slope) is within Cleveland \& Weidemann's (1993) reliable limits, while the second coefficient (the function curvature) is smaller and outside of those limits, probably because our data contained fewer points with high optical density values $(-0.4)$. 


\section{Comparison among different $\beta$ factor correction algorithms}

The reliability of the proposed algorithm was estimated using 6 pairs of spectra of natural samples obtained from the Galician coast during 1994. It was also compared to the $O D_{\text {sus }}(\lambda)$ values predicted by other algorithms (Kishino et al. 1986, Mitchell \& Kiefer 1988, Cleveland \& Weidemann 1993). The error when averaged over all wavelengths and samples was $8 \%$ when using a constant $\beta$ factor of 2.45 , equivalent to a 0.40 slope in a linear fit of the same data used to find Eq. (13) (Kishino et al. 1986). The average error was $11 \%$ with Mitchell \& Kiefer's (1988) algorithm (equation taken from Bricaud \& Stramski 1990). Cleveland \& Weidemann's (1993) estimation gave a lower deviation $(3 \%)$, while with Eq. (13) the error was only $1 \%$.

Fig. 6 shows several estimations of $\operatorname{OD}_{\text {sus }}(\lambda)$ against $O D_{\text {sus }}(\lambda)$ of natural samples. In those cases in which our algorithm underestimates (Fig, 6a), the Cleveland \& Weidemann (1993) algorithm gives values closer to those of suspension; in cases in which our algorithm overestimates, the opposite happens (Fig. 6b).

The results obtained from Eq. (13) differ by $2 \%$ (when averaged over all wavelengths and samples) from the estimations performed with Cleveland \& Weidemann's (1993) algorithm. Comparing the 2 equations, we can observe that when the optical density increases, the differences in the estimated values increase, while the differences between both estimations are $<0.01$ OD units when $O D_{\text {filter }}=0.3$, which means an approximate $3 \%$ of variation between the 2 estimations. In natural samples, such high values of optical density on filter are seldom reached once the absorption due to
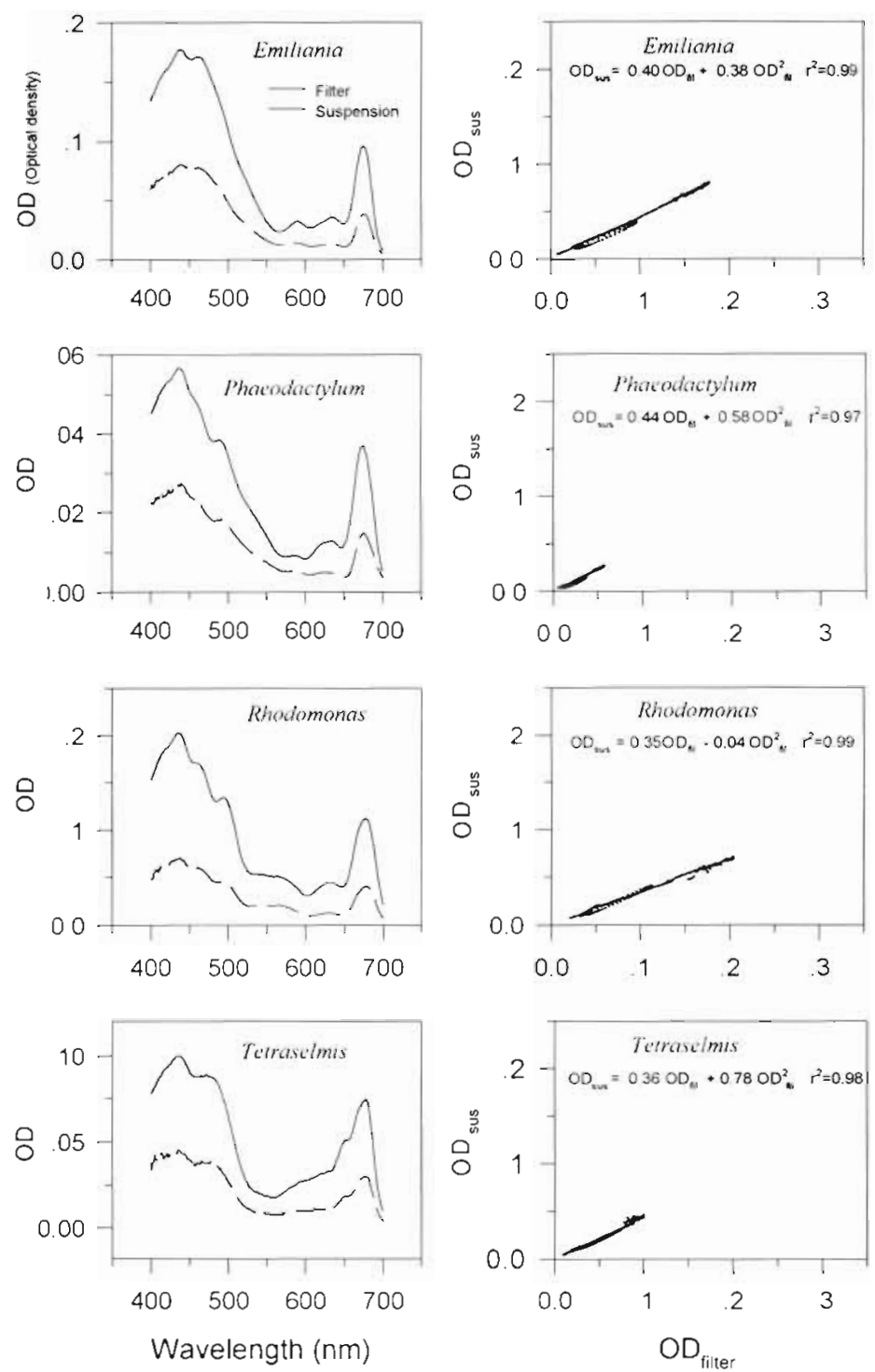

Fig. 3. Spectral values of OD on GF/F filter (solid line) and in suspension (dashed line) for 4 phytoplankton cultures (left side) and spectral optical densities measured on cuvette as a function of spectral optical densities measured on filters for each culture (right side)

Table 2. Quadratic and linear fits of 3 different concentrations of Pavlova gyrans and Emiliania huxleyi

\begin{tabular}{|c|c|c|c|c|c|}
\hline $\begin{array}{c}\text { Concentration } \\
\text { OD max }\end{array}$ & & Quadratic equation & & Linear estimation & \\
\hline \multicolumn{6}{|l|}{ Pavlova gyrans } \\
\hline 0.26 & $\mathrm{OD}_{\text {sus }}(\lambda)$ & $=0.370 D_{\text {filler }}(\lambda)+0.10 \mathrm{OD}_{\text {fitter }}^{2}(\lambda)$ & $\mathrm{r}^{2}=0.994$ & $O D_{\text {sus }}(\lambda)=0.40 O D_{\text {filler }}(\lambda)$ & $r^{2}=0.990$ \\
\hline 0.36 & $O D_{\text {sus }}(\lambda)$ & $=0.36 \mathrm{OD}_{\text {filter }}(\lambda)+0.27 \mathrm{OD}_{\text {filler }}^{2}(\lambda)$ & $\mathrm{r}^{2}=0.993$ & $O D_{\text {sus }}(\lambda)=0.44 O D_{\text {filler }}(\lambda)$ & $\mathrm{r}^{2}=0.988$ \\
\hline 0.5 & $\mathrm{OD}_{\text {sus }}(\lambda)$ & $=0.45 \mathrm{OD}$ filter $(\lambda)+0.23 \mathrm{OD}_{\text {filter }}^{2}(\lambda)$ & $r^{2}=0.994$ & $\mathrm{OD}_{\text {sus }}(\lambda)=0.54 \mathrm{OD}_{\text {filter }}(\lambda)$ & $r^{2}=0.988$ \\
\hline \multicolumn{6}{|l|}{ Emiliania huxleyi } \\
\hline 0.15 & $\dot{U} U_{\text {sus }}(\lambda)$ & $=U .4 \cup \cup \bar{U} J_{\text {tilles }}(\dot{\lambda})+\dot{0} .3 \overline{8} \bar{O} \bar{D}^{2}$ falter $(\dot{\lambda})$ & $\mathrm{r}^{2}=0 . \overline{9} \bar{y} 5$ & $\bar{U} \bar{D}_{\text {sus }}(\hat{\lambda})=\bar{U} .45 \bar{O} \bar{D}_{\text {filter }}(\hat{\Lambda})$ & $\mathrm{r}^{2}=\bar{u} \cdot \bar{y} \bar{y}$ \\
\hline 0.18 & $\mathrm{OD}_{\text {sus }}(\lambda)$ & $=0.41 \mathrm{OD}_{\text {filter }}(\lambda)+0.30 \mathrm{OD}^{2}$ tilter $(\lambda)$ & $r^{2}=0.994$ & $O D_{\text {sus }}(\lambda)=0.46 O D_{\text {rilter }}(\lambda)$ & $r^{2}=0.99$ \\
\hline 0.20 & $O D_{\text {sus }}(\lambda)$ & $=0.42 \mathrm{OD}_{\text {filter }}(\lambda)+0.42 \mathrm{OD}_{\text {filter }}^{2}(\lambda)$ & $r^{2}=0.992$ & $O D_{\text {sus }}(\lambda)=0.49 O D_{\text {filter }}(\lambda)$ & $r^{2}=0.988$ \\
\hline
\end{tabular}



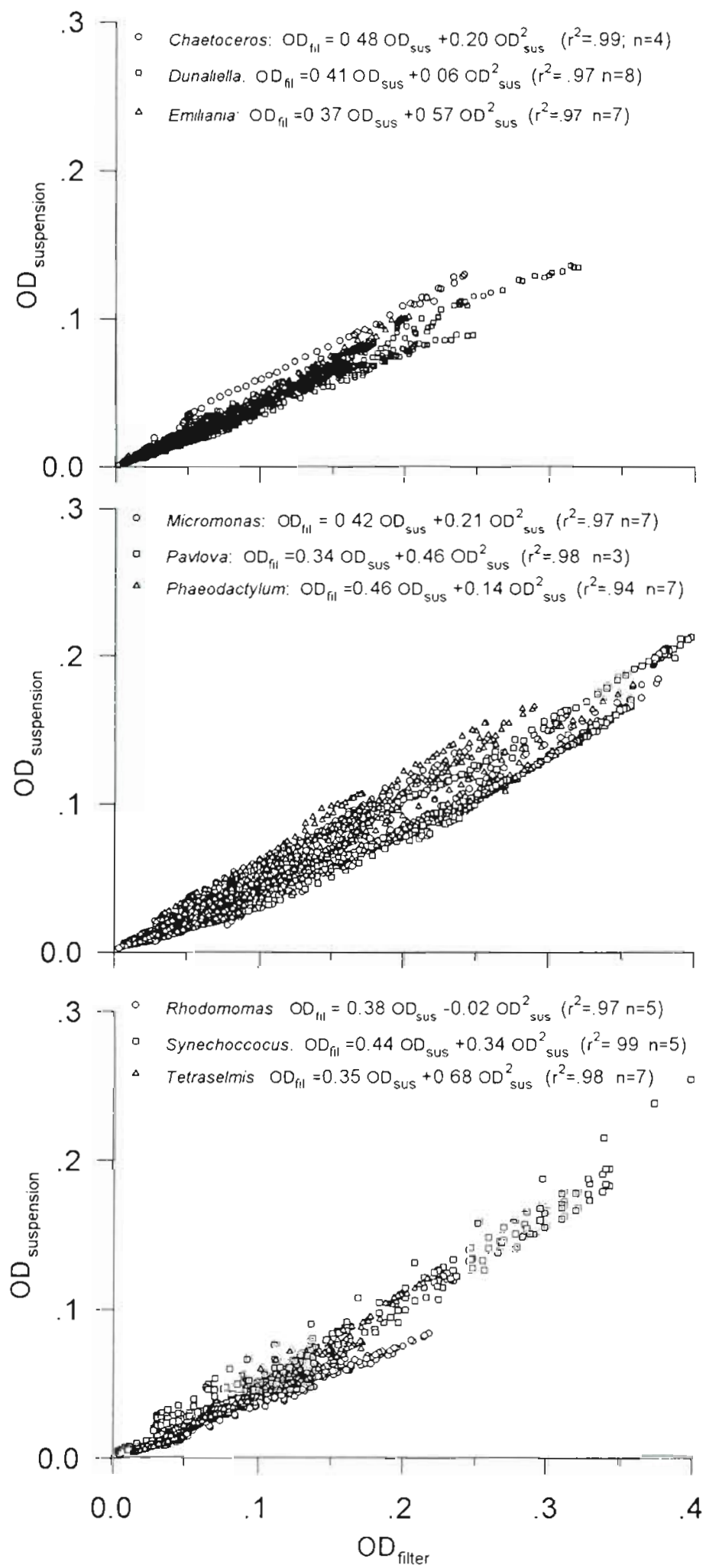

Fig. 4. Spectral optical densities in suspension as a function of spectral optical densities on filter for the 9 species. Quadratic equations, coefficients of determination, $\left(r^{2}\right)$, and number of spectra ( $n$ ) are shown for each species. Spectra are plotted from 400 to $700 \mathrm{~nm}$ at $4 \mathrm{~nm}$ spectral bandwidth. Equations were fitted at $1 \mathrm{~nm}$ intervals

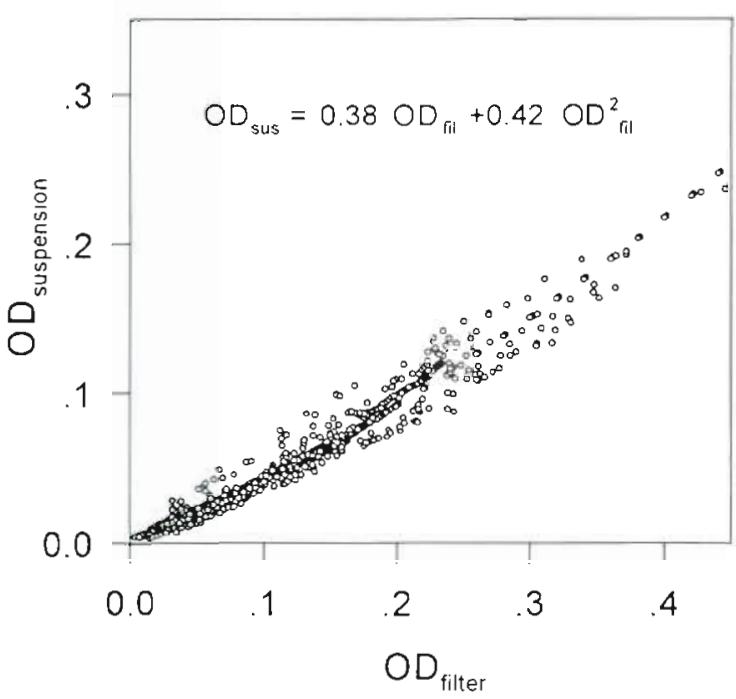

Fig. 5. Spectral OD in suspension as a function of spectral OD on filter for the 9 species, 52 cultures. Only 13 points of each spectrum (every $25 \mathrm{~nm}$ ) are plotted

nonalgal matter has been eliminated; therefore, differences must be smaller.

These variations between the 2 algorithms are unimportant, as the variability found when performing several absorption spectra in natural samples is greater than the average error occurring in the estimation when using any of the equations, Variability in $\operatorname{OD}_{\text {filter }}(\lambda)$ [corrected in volume and area through Eq. (3)] on filtering different volumes from the same seawater sample can reach $20 \%$ at certain wavelengths. Besides, the absorption spectra of samples in suspension are hardly reproducible, as natural samples have aggregates, species with different sizes and shapes, that make the absorption spectra vary when several measurements are taken on the same sample. Normally, errors found when making estimations of absorption spectra vary along the visible spectrum, demonstrating that different algorithms are closer to the real values in regions where absorption is high (peaks). In the valley areas, the estimated errors are greater (Fig. 6), as in these regions the optical density values are low; therefore, the accuracy of the spectrometer readings is lower.

Both the algorithm proposed by Cleveland \& Weidemann (1993) and the one proposed in this study are suitable for correcting pathlength amplification due to the concentration on $\mathrm{GF} / \mathrm{F}$ filters of the particulate matter in suspension of seawater samples. 


\section{Estimation of the spectral absorption coefficients of phytoplankton by reconstructed spectra}

A comparison was made between the phytoplankton absorption spectra coefficients measured by the wet filter method corrected for the pathlength amplification factor and the HPLC reconstructed phytoplankton absorption spectra (Bidigare et al. 1990) from 20 natural samples. Samples were collected at the subsurface chlorophyll maximum depth (chl max) and at the 1\% light depth in 2 different areas: in the shelf break front in the north of the Galician coast (spring), and in an estuarine upwelling system (Ría de Vigo).

During the comparison of the 2 spectra, an overestimation of the absorption spectra reconstruction was found. Assuming that the pigment absorption spectrum $\left[\alpha^{*}\right.$ ph-sol $\left.(\lambda)\right]$ estimated by the reconstruction method is correct, the differences between $\vec{a}^{*}{ }_{\text {ph-sol }}(\lambda)$ and $a_{p h}^{*}(\lambda)$ are due to the package effect (Sathyendranath et al. 1987). A comparison between $a^{*}{ }_{p h-s o l}(675)$ and $a^{*}{ }_{p h}(675)$, where chlorophyll is the only pigment responsible for the absorption (Nelson et al. 1993), can indicate the existence of the package effect. Significant differences were found in 13 of 20 samples (Table 3), indicating the existence of the package
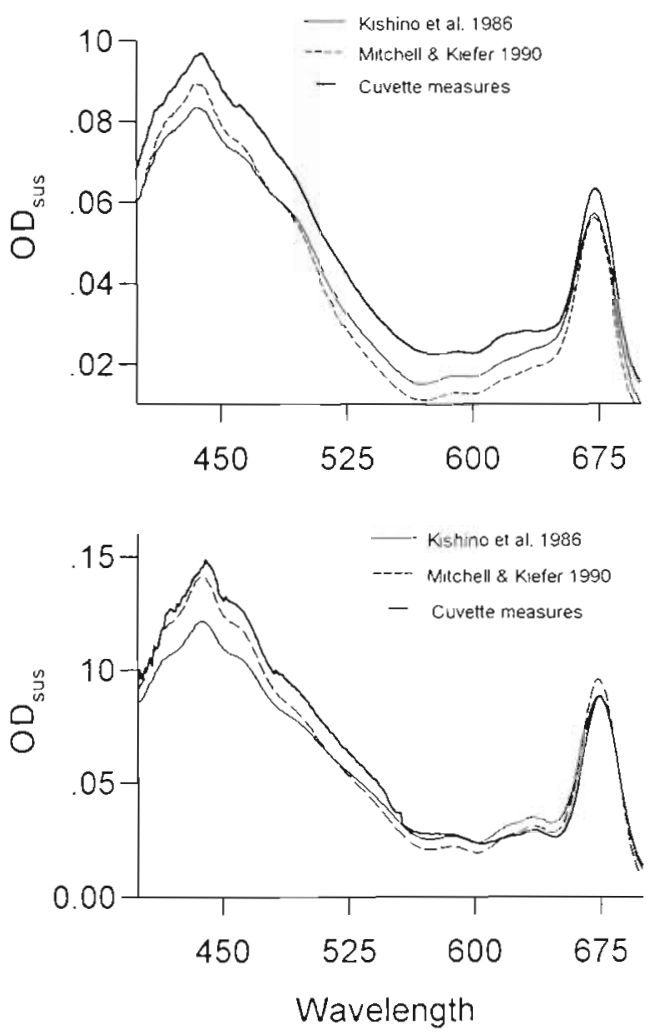

Table 3. Values of the fractional reduction of pigment absorption due to the package effect calculated according to Eqs. (9) and $(10)$

\begin{tabular}{|c|c|c|}
\hline Station & $\frac{3 Q_{d}(675)}{2 \rho^{\prime}(675)}$ & $\frac{a^{*}{ }_{p h}(675)}{a_{p h-s o l}^{*}(675)}$ \\
\hline \multicolumn{3}{|l|}{ Coastal } \\
\hline T6 & 0.59 & 0.57 \\
\hline C5 & 0.87 & 1.05 \\
\hline 17 & 0.91 & 0.52 \\
\hline $18-0$ & 0.90 & 1.05 \\
\hline $18-30$ & 0.67 & 0.93 \\
\hline C 16 & 0.89 & 0.96 \\
\hline \multicolumn{3}{|c|}{ Estuarine } \\
\hline R1 & 0.68 & 1.02 \\
\hline $\mathrm{R} 2$ & 0.49 & 0.75 \\
\hline R3 & 0.12 & 0.8 \\
\hline R5 & 0.23 & 0.8 \\
\hline R6 & 0.42 & 1.06 \\
\hline R7 & 0.3 & 0.34 \\
\hline R8 & 0.47 & 0.55 \\
\hline R9 & 0.17 & 0.95 \\
\hline R10 & 0.19 & 0.87 \\
\hline R11 & 0.09 & 0.63 \\
\hline $\mathrm{R} 12$ & 0.27 & 0.27 \\
\hline R13 & 0.74 & 0.5 \\
\hline SR 1 & 0.18 & 0.47 \\
\hline SR2 & 0.63 & 0.84 \\
\hline
\end{tabular}
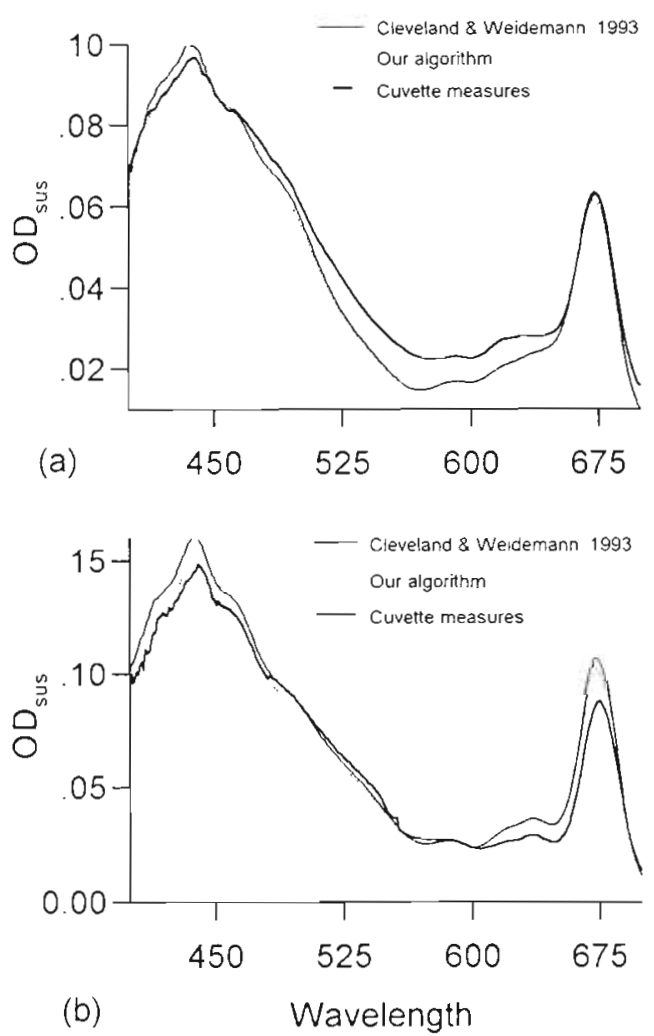

Fig. 6. Spectral values of absorption (OD) of living phytoplankton in suspension obtained by different estimations: Kishino et al. (1986), Mitchell \& Kiefer (1990), Cleveland \& Weidemann (1993) and our algorithm, and the absorption measured from the suspension for 2 natural samples 

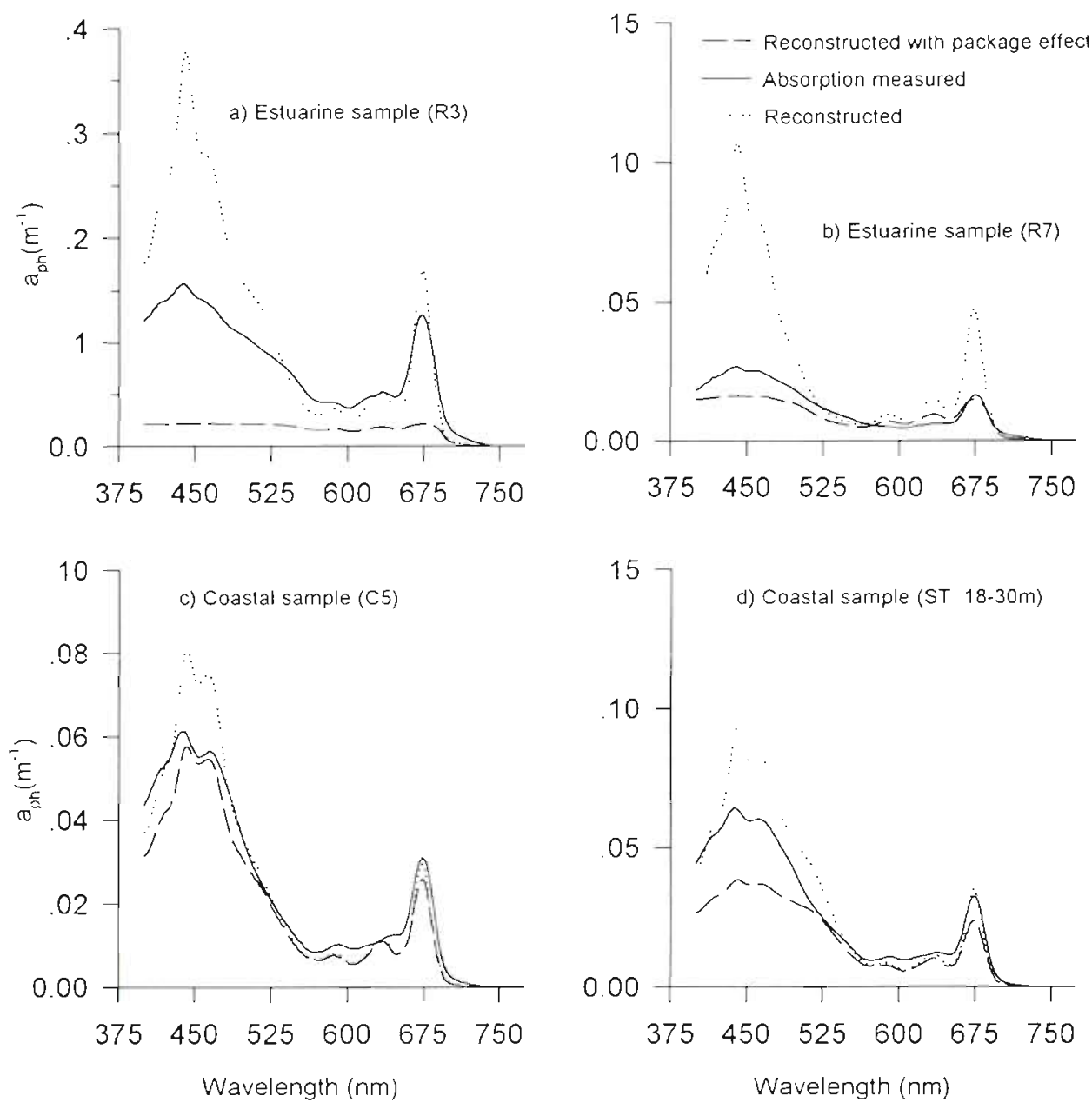

Fig. 7. Phytoplankton absorption coefficient spectra, $a_{p h}\left(\mathrm{~m}^{-1}\right)$, in natural samples. Companson is made between absorption spectra, reconstructed spectra without consideration of the package effect. and reconstructed spectra with consideration of the package effect for coastal and estuarine samples

effect. When the package effect was estimated by Eq. (9) all the samples showed a generally higher package (Table 3). The package effect was estimated (Morel \& Bricaud 1981, Nelson et al. 1993) and the comparisons were performed with the reconstructed spectra (Eq. 7) corrected for the package effect $\left[a_{\mathrm{ph}}(\lambda)\right]$.

In the coastal samples, $a_{p h}^{\wedge}(\lambda)$ underestimated $a^{*}{ }_{p h}(\lambda)$ by between 4 and $35 \%$ when the average was calculated from the whole visible spectrum (400 to $700 \mathrm{~nm}$ ). In the estuarine samples, the differences were higher and ranged from 12 to $70 \%$ (Fig. 7). In some cases the differences were even greater after correcting the package effect than before (Fig. 7). The correction done according to Eq. (7) assumes a spherical and homogeneous shape of the cells to obtain the average diameter $d$ (estimated from the biovolume) and the intracellular concentration of chl a per cellular volume unity $\left(C_{1}\right)$; however, the natural samples used in this study came from a coastal area in which the phytoplankton shape diversity is very high and complex, and where large diatoms and dinoflagellates are important components of the phytoplankton community (Table 4). Consequently, the assimilation of the shape of these phytoplankton species to spherical forms conveys a lower surface:volume ratio. This strong overestimation of the package effect can be also visualised comparing the $Q_{d}^{*}(675)$ estimated from Eq. (9) with $Q_{d}^{*}(675)$ calculated from the relationship of the specific spectra absorption coefficients obtained by both methods [Eq. (10), Table 3].

According to Nelson et al. (1993) the package effect of the phytoplankton in coastal areas is normally low, and that is how it looks when observing the spectra (Fig. 7).

Only in 2 of 20 samples were the absorption coefficients obtained by both methods were in relative 
Table 4. List of species in order of importance (in terms of volume) of samples represented in Fig. 7

\begin{tabular}{|llll|}
\hline a) Estuarine sample (R3) & b) Estuarine sample (R7) & c) Coastal sample (C5) & d) Coastal sample (18-30 m) \\
\hline Rhizosolenia setigera & Mesodinium rubrum & Ceratium tripos & Pleurosigma ibericum \\
Pseudo-nitzschia spp. & Small flagellates & Monads 3-5 $\mu \mathrm{m}$ & Pseudo-nitzschia pungens \\
R. imbricata var. shrub & Cryptophyceae spp. & Monads $5-8 \mu \mathrm{m}$ & Monads $3-5 \mu \mathrm{m}$ \\
Leptocylindrus danicus & Gymnodinium sp. (medium) & Monads $8-10 \mu \mathrm{m}$ & Monads $5-8 \mu \mathrm{m}$ \\
Mesodinium rubrum & Cachonina niei & Dinoflagellates $<30 \mu \mathrm{m}$ & Ceratium furca \\
Stephanopyxis turris & Gymnodinum sp. (small) & Centric diatom spp. & Dinoflagellates $<30 \mu \mathrm{m}$ \\
\hline
\end{tabular}

agreement (5 and $10 \%$ difference), and these were samples dominated by small cells with quasi-spherical shapes (small flagellates and small diatoms; Fig. $7 \mathrm{c}, \mathrm{d}$; Table 4).

\section{CONCLUSIONS}

The hysteresis effect, firstly recognised by Bricaud \& Stramski (1990), was also seen in our work and was attributed to the relatively high contribution of nonpigmentary material (i.e. cell debris, detritus) in relation to pigment signals in the low absorption regions of the spectra. In these regions the pigment signals have a very low absorbance in cuvette, but recovered on the filter $O D$ readings with the pathlength amplification. This difference between the spectra results in a loop in the $O D_{\text {sus }}$ versus $O D_{\text {fitter }}$ relationship, giving a curve for the blue-green regions different from that for the red region of the spectra. When the spectra were corrected for detritus using the Bricaud \& Stramski (1990) method, the hysteresis effect was reduced considerably, confirming that it was a result of the interference of the non-pigmentary material

The pathlength amplification factor $(\beta)$ found with 52 pairs of spectra of 9 phytoplankton cultured species, after the correction of the hysteresis effect, showed a good agreement $1 \%$ of average deviation in the visible spectrum) with spectra of natural seawater samples measured in cuvette. Our equation for the pathlength amplification factor is very similar to that found by Cleveland \& Weidemann (1993) showing $2 \%$ of average differences when applied to the same natural samples. This result suggests that a unique equation for $\beta$ correction can be used for seawater samples with a mixed phytoplankton population. However, when the research is focused in monoalgal cultures a specific equation must be determined because differences in the optical density relationships were observed between species

The results obtained by comparing reconstructed phytoplankton absorption spectra (Bidigare et al. 1990) of natural seawater samples with those obtained by the wet $\mathrm{GF} / \mathrm{F}$ filter technique indicate that spectra recon- struction is suitable whenever the sample species population does not differ excessively from the spherical shape (probably in open ocean waters). In natural samples with a high diversity of shapes, as in upwelling coastal areas, determination of absorption coefficients by filter concentration is more reliable, as well as fast and simple, allowing more exhaustive sampling to take place.

Acknowledgements, We thank J. L. Garrido for his help with algal culture growth, and A. M. Mosquera and M. Varela for the phytoplankton determinations. Comments by 3 anonymous reviewers are acknowledged. This research was funded by ClCYT project AMB93-0129. The work of B.A. was supported by a predoctoral grant from Xunta de Galicia.

\section{LITERATURE CITED}

Berner T, Dubinsky Z, Wyman K, Falkowski PG (1989) Photoadaptation and the package effect in Dunaliella tertiolecta (Chlorophyceae). J Phycol 25:70-78

Bidigare RR, Morow MW, Kiefer DA (1989a) Derivative analysis of spectral absorption by photosynthetic pigments in the western Sargasso Sea. J Mar Res 47:323-341

Bidigare RR, Ondrudek ME, Morow MW, Kiefer KA (1990) In vivo absorption properties of algal pigments. SPIE Ocean Optics X 1302:290-302

Bidigare RR, Schofield O. Prezelin BB (1989b) Influence of zeaxanthin on quantum yeld of photosynthesis of Synechococcus clone WH7803 (DC2). Mar Ecol Prog Ser 56:177-188

Bricaud A., Stramski D (1990) Spectral absorption coefficients of living phytoplankton and nonalgal biogenous matter: a comparison between the Peru upwelling area and the Sargasso Sea. Limnol Oceanogr 35:562-582

Butler WL (1962) Absorption of light by turbid materials. J Opt Soc Am 52:292-299

Cleveland JS, Weidemann AD (1993) Quantifying absorption by aquatic particles: a multiple scattering correction for glass-fiber filters. Limnol Oceanogr 38:1321-1327

Cleveland JS, Perry MJ (1994) A model for partitioning partıculate absorption into phytoplanktonic and detrital components. Deep Sea Res 41:197-221

Davies-Colley RJ (1983) Optical properties and reflectance spectra of 3 shallow lakes obtained from a spectrophotometric study. NZ J Mar Freshwat Res 17:445-459

Edler L (1979) Recommendations for manne biological studies in the Baltic Sea. Phytoplankton and chlorophyll. Balt Mar Bivi 5

Figueiras FG, Niell FX (1987) Composición del fitoplancton en la Ría de Pontevedra (NO de España). Invest Pesq 51. $371-409$ 
Garrido JL, Zapata M (1993) High performance liquid chromatographic separation of polar and non-polar chlorophyll pigments from algae using a wide pore polymeric octadecylsilica column. J High Res Chrom 16: $229-233$

Guillard RRL, Ryther JH (1962) Studies of marıne planktonic diatoms. I. Cyclotella nana Hadstedt and Detonula confervacea (Cleve). Can J Microbiol 18:229-239

Iturriaga R, Mitchell BG, Kiefer DA (1988) Microphotometric analysis of individual particle absortion spectra. Limnol Oceanogr 33:128-134

Jeffrey SW (1980) Algal pigment systems. In: Falkowski PG (ed) Primary productivity in the sea. Plenum Press, New York, p 33-58

Kiefer DA, Soohoo JB (1982) Spectral absorption by marine particles of coastal waters of Baja California. Limnol Oceanogr 27:492-499

Kirk JTO (1980) Spectral absorption properties of natural waters: contribution of the soluble and particulate fractions to Iight absorption in inland water of southeastern. Australia. Aust J Mar Freshwat Res 31:287-296

Kirk JTO (1983) Light and photosynthesis in aquatic ecosysiems. Cambridge Universily Press, Cambidye

Kishino M, Okami N, Takahashi M, Ichimura S (1986) Light utilization efficiency and quantum yield of phytoplankton in a thermally stratified sea. Limnol Oceanogr 31 $557-566$

Kishino M, Takahasti N, Okami N, Ichimura S (1985) Estimâtion of the spectral absorption coefficients of phytoplankton in the sea. Bull Mar Sci 37:634-642

Lewis MR, Warnock RE, Platt T (1985) Absorption and photosynthetic action spectra for natural phytoplankton populations implications for production in the open ocean. Limnol Oceanogr 30:794-806

Margalef R, Durán M, Saiz F (1955) El fitoplancton en la Ría de Vigo de enero de 1953 a marzo de 1954. Invest Pesq II: $83-130$

Mitchell BG, Kiefer DA (1984) Determination of absorption and fluorescence excitation spectra for phytoplankton. In: Holm-Hansen O, Bolis L, Gilles R (eds) Marine phytoplankton and productivity: proceedings of the invited lectures to a symposium organized within the 5 th conference of the European Society for Comparative Physiol. ogy and Biochemistry. Sprunger, Berlın, p 157-169

This article was submitted to the editor
Mitchell BG, Kiefer DA (1988) Chlorophyll a specific absorption and fluorescence excitation spectra for light-limited phytoplankton. Deep Sea Res 35:639-663

Moore LR, Goericke R, Chisholm SW (1995) Comparative physiology of Synechococcus and Prochlorococcus: influence of light and temperature on growth, pigments, fluorescence and absorption properties. Mar Ecol Prog Ser $116: 259-275$

Morel A, Bricaud A (1981) Theoretical results concerming light absorption in a discrete medium, and application to specifiec absorption of phytoplankton. Deep Sea Res 28A $1375-1393$

Morrow JH, Chamberlin WS, Kiefer DA (1989) A two-component description of spectral absorption by marine partıcles. Limnol Oceanogr 35:1500-1509

Nelson NB, Prézelin BB (1990) Chromatic light effects and physiological modeling of absorption properties of Heterocapsa pygmaea (= Glenodinium sp.). Mar Ecol Prog Ser 63:37-46

Nelson NB, Prérelin BB, Bidigare RR (1993) Phytoplankton light absorption and the package effect in Califormia coastal waters. Mar Ecol Prog Ser 94:219-227

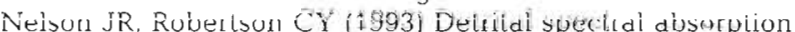
Laboratory studies of visible light effects on phytodetritus absorption, bacterial spectral signal, and comparison to field measurements. J Mar Res 51:181-207

Sathyendranath S, Lazzara L, Prieur L (1987) Variations in the spectral values of specific absorption of phytoplanktor. Limnol Oceanogr 32:403-415

Shibata K (1958) Spectrophotometry of intact biological materials. Absolute and relative measurements of their transmission, reflection and absorption spectra. Biochemistry 45:599-623

Shibata K, Benson AA, Calvin M (1954) The absorption of suspensions of living micro-organisms. Biochim Biophys Acta 15:461-470

Truper HQ, Yentsch CS (1967) Use of glass fiber filter for the rapid preparation of in vivo absorption spectra of photosynthetic bacteria. J Bacteriol 947:1255-1256

van de Hulst HC (1957) Light scattering by small particles. John Wiley, New York

Yentsch CS (1962) Measurement of visible light absorption by particulate matter in the ocean. Limnol Oceanogr 7 : $207-217$

Manuscript furst recelved: August 1, 1995

Revised version accepted: February 15, 1996 